\title{
De custodios y valedores: dedicatorias y dedicatarios en las ediciones del teatro de Moreto en el siglo XVII*
}

\section{Custodians and Protectors: Dedications and Recipients in the Seventeenth-Century Editions of Moreto's Plays}

CARMEN SANZ AYÁN

Universidad Complutense de Madrid-Real Academia de la Historia

Facultad de Geografía e Historia, Edificio B

C/ Profesor Aranguren, s/n. Madrid, 28040

euridice@ghis.ucm.es

Orcid ID 0000-0003-0280-2755

Resumen: El trabajo analiza la "utilidad social" que tuvieron las ediciones del teatro de Moreto durante el siglo XVII, a través del estudio de las dedicatorias. Este planteamiento metodológico, pone el foco de la investigación en el dedicatario de los volúmenes y en el contexto social, político y cultural que envolvió ese proceso. En el caso de la edición de la Primera parte de las comedias de Moreto (1654), el volumen parece insertarse en un programa general de autopromoción del vill duque de Alburquerque conectado con otras obras y otros autores que pudieron formar su clientela cultural. Caso distinto sería el de los editores del teatro de Moreto tras su muerte. Estos mercaderes de libros dedican la obra a "nobles nuevos" e incluso a otros personajes de inferior categoría social, que pudieron subvencionar en todo o en parte la edición, para bruñir el origen familiar de los dedicatarios hasta hacerlo asimilable con su nuevo estatus social.

Palabras clave: Dedicatorias. Mercaderes de libros. Nobleza nueva. vIII Duque de Alburquerque. Moreto.
Abstract: The work analyzes, through the study of the dedications, the "social utility" that the editions of the Moreto's plays had during the seventeenth century. This methodological approach places the focus of the research on the dedications of the volumes and on the social, political and cultural context that involved that process. In the case of the edition of the First part of the works of Moreto (1654), the volume seems to be inserted in a general program of self-promotion of the vIII Duke of Alburquerque connected with other works and other authors that could be part of their cultural patronage. A different approach is observed when analysing the work of the editors of the Moreto's plays after his death. These publishers dedicate the work to "new nobles" and even to other characters of lower social status, who could subsidize all or part of the edition, so that in the text of the dedication, their family origin will be improved, assimilating thus more easily to his new superior social status.

Keywords: Dedications. Book Publishers. New Nobility. vIII Duke of Alburquerque. Moreto.

\footnotetext{
* Este trabajo se enmarca en el ámbito del proyecto de investigación del Programa de Excelencia MINECO. Gobierno de España, titulado Elites financieras y burocráticas de la Monarquía Hispánica: redes de solidaridad nobiliaria, patronazgo y estrategias de familia (1621-1725). Ref. HAR2015-69143-P.9
} 
E 128 de octubre de 1669 moría Agustín Moreto en Toledo. Su fallecimiento le impidió solo por unos meses participar en un nuevo ciclo de fiestas teatrales en Palacio. Durante sus últimos años de vida retirado en la ciudad imperial, pudo contemplar cómo en la gobernación de la Monarquía se estaba librando una inquietante batalla entre la reina regente Mariana de Austria, responsable política durante la minoría de Carlos II y don Juan de Austria, el hijo ilegítimo pero reconocido de Felipe IV.

La gobernadora, apoyada en su valido y confesor el austriaco Juan Everardo Nithard, ejerció sus funciones asesorada por una Junta de Gobierno pero hubo de enfrentarse a un don Juan desafiante que, sin entrar en pormenores, le obligó por la fuerza a deshacerse de su valido y a remodelar aquel organismo asesor. Tras las cesiones, a finales de marzo de 1669, la facción de la Regente con un Nithard expulsado de la corte, intentó recuperar la iniciativa política y decidió formar un regimiento de la Guardia del Rey en Madrid para neutralizar cualquier amenaza militar venidera. Finalmente en junio de 1669, a escasos tres meses de la muerte de nuestro dramaturgo, don Juan aceptó el nombramiento de Vicario General de la Corona de Aragón lo que significaba su alejamiento temporal de Madrid.

Después de la remodelación forzada del entorno gubernativo de Mariana (Maura 183), muchos de los que se habían instalado recientemente en los puestos de poder mostraron su inclinación a reanudar la actividad dramáticorepresentativa palaciega y en enero de 1670 todo eran fiestas en la Corte. Comenzó así un nuevo ciclo teatral en el que Moreto ya no pudo participar. Sí lo había hecho en el de los años cincuenta del siglo XVII; sobre todo cuando las celebraciones empezaron a ser responsabilidad del marqués de Heliche tras el segundo matrimonio de Felipe IV con su, por entonces, jovencísima sobrina Mariana (Flórez 180).

En ese contexto Moreto había escrito el baile entremesado de El Mellado, dedicado al mundo del hampa, que sirvió para celebrar, en 1655, el cumpleaños de la hermana mayor de Carlos II, Margarita Teresa. También en ese año se representó en Madrid su Loa para los años del Emperador de Alemania, dedicada a Fernando III, el padre de la reina (Lobato 128).

Parece que la apertura de ese ciclo representativo, propició la impresión de comedias como lo demuestra que en esos años Moreto eligiera dar un impulso definitivo al conocimiento y a la difusión de su obra dramática con la edición, en 1654, de la Primera parte de sus comedias (Cotarelo 451). El 8 de julio de ese año obtuvo la licencia que le permitía imprimirlas durante una dé- 
cada, aunque inmediatamente la entregó -suponemos que bajo contrato-, al mercader de libros, Mateo de la Bastida, conocido por comercializar, entre otras, las obras de Quevedo (Moll 460). En este caso el editor también hizo la inversión fundamental para pagar al impresor de la obra, Diego Díaz de la Carrera (Zugasti 65).

Moreto dedicó el primer volumen de sus comedias, que fue su única compilación hecha en vida, a don Francisco Fernández de la Cueva (16191676), vIII Duque de Alburquerque, Marqués de Cuéllar y también tras su matrimonio, Marqués de Cadereita, Conde de Ledesma y Huelma, además de señor de las villas de Monbeltrán y la Codosera². Estrenaba don Francisco, en esos precisos momentos en los que Moreto le ofreció su obra, el cargo de Virrey y Capitán General de las Provincias de Nueva España (Rubio 249). La Relación clientelar del dramaturgo con Alburquerque parecía muy estrecha a tenor de los contenidos de la dedicatoria. Se reconocía en ese texto como humilde criado suyo y le llama "protector de ingenios" y "Mecenas". La influencia del origen familiar mercantil del poeta se aprecia en el paratexto ya que dice ser Mercader como lo era su padre, aunque en este caso solo ambicioso de aplausos y no de riquezas y, para continuar con el símil, decía poner su trabajo bajo la protección de Alburquerque y de su red clientelar, convencido de que su libro embarcaría a las Indias, como lo hacían el resto de mercancías, para que, con ayuda del dedicatario, ganara "ciento por ciento" (Moreto 1654,2$)$.

La impresión de esta Primera parte de sus comedias fue solo un poco posterior en el tiempo al nombramiento de Alburquerque como Capitán General y Virrey de las Provincias de Nueva España de modo que, para el noble titulado, supuso también un gesto simbólico que le permitía visibilizar ese nuevo y deseado destino al servicio del rey Felipe IV, a la par que era un homenaje a sus virtudes proclamadas en letras de molde. Un destino que, además, prolongaba una tradición familiar. De hecho, cuando el libro de Moreto vio la luz, el duque ya se encontraba en Nueva España tras haber hecho su solemne entrada en Ciudad de México el 15 de agosto de 1653, después de quince años de iniciar sus servicios a la Monarquía (Rubio 150).

Francisco Fernández de la Cueva había nacido en Barcelona en 1619. Comenzó su carrera militar en 1638 como soldado de pica en el tercio del marqués de Mortara en el sitio de Fuenterrabía. Amigo del duque de Osuna

1 Son los títulos que figuran en la portada de la Parte Primera de Comedias de D. Agustín Moreto. 
con el que protagonizó algunas correrías de juventud, una vez regresó a Madrid ascendió con gran rapidez a distintos puestos militares en la guerra de Flandes (Rodríguez Villa 338), seguramente por sus capacidades y méritos pero no cabe duda que en ello influyó también su elevado origen familiar. A partir de 1641 comandó un tercio de infantería propio y en 1642 destacó en la batalla de Châtelet (26 de mayo de 1642) en la que ejerció de maestre de campo bajo las órdenes del gobernador de Flandes Francisco de Melo (Melo 406).

No obstante en su carrera militar, el desenlace de la batalla de Rocroi (19 de mayo de 1643) supuso un tropiezo considerable. Fue un episodio más de los enfrentamientos con Francia contextualizado en la Guerra de los Treinta Años, pero muy simbólico por ser la primera derrota reconocida de los tercios españoles ante las tropas francesas. El gran número de bajas y el hecho de que él sobreviviera, necesitó una justificación que el propio Alburquerque dio por carta enviada de su puño y letra a Felipe IV:

No es faltar a la modestia informar a V.Mg de la verdad. No hubo grueso nuestro que yo no le llevase a la carga, ni peligro que yo no buscase por mejorar el estado de la batalla. Prisionero estuve dos veces y me libré con la espada. Ningún día me he debido tanto al servicio de V.Mg y ninguno me ha debido menos mi vida, pero ni el no perderla ni el perderse la ocasión, dependió de mí ni de los medios humanos. (Rodríguez Villa 345)

En respuesta a sus explicaciones Felipe IV disculpó aquel suceso con otra carta escrita de manos del secretario Jerónimo de Villanueva el 30 de junio de 1643 en la que disculpaba a Alburquerque pues:

Aunque el suceso de la batalla de Rocroy fue infeliz, habiendoos señalado en ella tan conforme a las obligaciones de vuestra sangre (de que me avisa el marqués de Tordelaguna [es decir, Melo], he querido deciros la estimación con que quedo del valor y zelo de mi servicio que mostrays en todas las ocasiones (...) y que vuestro exemplo animará a todos a cumplir con sus obligaciones. (Rodríguez Villa 346)

Cuando don Francisco regresó a Madrid ejerció de modo efectivo su primer cargo palatino, el de Gentilhombre de Cámara que le había sido otorgado en 1642.

Tres años después, a principios de 1645 (12 de enero) contrajo matrimonio con Juana Francisca Díez de Aux y Armendáriz, hija del primer marqués de Cadereita (Vargas 226) y una de las damas de la difunta reina Isabel de Bor- 
bón. La carrera palatina de esta dama fue larga, pues, tras la muerte de la reina Isabel, fue nombrada Camarera Mayor de la Infanta Margarita, primera hija de Mariana de Austria y más tarde, ya viuda, ocupó el mismo cargo con las reinas María Luisa de Orléans y Mariana de Neoburgo (Maestro).

Pero a pesar de la integración de Alburquerque en la vida palatina -por sí mismo y por la vía del matrimonio-, y de la comprensión que Felipe IV le manifestó a través de la relación epistolar, es posible que creyera necesario emprender un programa de mejora de su imagen en la que, el auspicio de la edición de la Primera parte de comedias de Moreto, pudo jugar un papel central aunque no único.

Procuró hacer visibles a través de la obra impresa, los triunfos cosechados con posterioridad a Rocroi en los que quedaba demostrada su pericia militar. Durante 1649 (Tercera relación 1649) y 1650, Alburquerque luchó en el frente catalán y acumuló victorias al lado de un don Juan José de Austria triunfante. Logros que se difundieron profusamente en relaciones de sucesos (Relación del Feliz Suceso 1649) pero también en panfletos que adoptaron la forma de cartas escritas en primera persona -muy al estilo de las que el hermanastro de Carlos II dio a la imprenta para procurar su propia autopromoción (Bremundán) - y que iban dirigidas al hermano de Alburquerque (Fernández de la Cueva 165) y al Arzobispo de Valencia (Fernández de la Cueva 1650) aunque al hacerlas públicas, tenían como objetivo una acción de propaganda que pretendía prestigiar la imagen de quien las protagonizaba. En ellas daba cuenta precisa en primera persona de las victorias en las que había participado y del papel protagonista que había jugado. De entre todos los episodios narrados el que alcanzó más difusión fue el que describía la toma con seis galeras de cuatro bajeles franceses que se produjo en las inmediaciones de Cambrils en noviembre de 1650. Un acontecimiento gozoso para las armas de Felipe IV del que existieron múltiples versiones (Relación de la Gran Victoria 1650). También tuvo amplio eco la acción organizada contra San Feliú que era el lugar por el que las tropas francesas burlaban el cerco al que estaba sometida Barcelona en junio de 1652 (Relación Puntual y verdadera 1652), en el contexto de la Guerra de Cataluña iniciada en 1640.

Estas noticias impresas daban cuenta de la proximidad con la que don Juan de Austria trabajaba al lado de Alburquerque y demostraban su amplio grado de conexión; por ejemplo, en el caso de la acción en San Feliú se dice que "don Juan resolvió executar lo que muchos días antes avía meditado, comunicando la forma y encargando la disposición al duque de Alburquerque" (1v). 
Pero la campaña de imagen no se limitó a las noticias que defendían su exitoso perfil militar a pesar del tropiezo de Rocroi. Dos años antes de que apareciera la Primera parte de las comedias de Moreto, en 1652, el autor lisboeta Antonio López de Vega (¿1586-1656?) dedicó a Alburquerque la segunda edición de El perfeto Señor. Una obra que, editada por primera vez en 1626, participaba en el largo y clásico debate sobre las armas y las letras en la educación del noble. El antibelicismo que el autor proclamaba se acercaba en el tono a la Querela Pacis de Erasmo (Laspéras 182). Pero más allá de los contenidos concretos, el patrocinio de la segunda edición de un tratado de esas características permitía a don Francisco trasmitir la imagen de un noble completo en todas las facetas de su desempeño. Por lo que sabemos, López de Vega cambió incesantemente de protectores a lo largo de su vida (Acquier 94), quizá tras la búsqueda de una consolidación social que nunca encontró. Se reconocía en la dedicatoria de la segunda edición de 1652 como criado de Alburquerque -igual que Moreto- y ensalzaba en el paratexto sus virtudes guerreras y cortesanas, además de su inclinación a hacer versos (López de Vega \$4) delineando un perfil de Francisco Fernández de la Cueva como noble "perfecto", incluida su faceta cortesana.

La culminación de la estrategia de visibilidad de Alburquerque a través de su acción cultural se produjo en 1653 cuando, además de aparecer como dedicatario en la Primera parte de las comedias de Moreto, se editaron casi al mismo tiempo los festejos mexicanos en torno a su llegada al virreinato de Nueva España. En ese texto la proyección de su imagen quedó asimilada con el "Marte Católico, Astro Político, planeta de héroes y ascendente de príncipes" (Farré 232). Con esta descripción superaba en excelencia al mismo referente simbólico de Marte, tal y como expuso en su momento Judith Farré. El programa iconográfico y la relación de su entrada, corrieron a cargo del mexicano Juan de Guevara, presbítero, capellán y confesor del monasterio de religiosas de Santa Inés de México, además de amigo y colaborador de Sor Juana Inés de la Cruz (Schmidhuber).

Parece que en el desempeño de su oficio Alburquerque, según Israel (254-62), resultó un virrey ejemplar en una época en la que las inercias y la corrupción habían hecho mella en el Virreinato de Nueva España. En este contexto, la edición de la Primera parte de las comedias de Moreto bajo su explícita protección, lejos de ser un acontecimiento cultural aislado y accidental, podría formar parte de un programa representativo propio de un gran noble en el camino de la restitución, mejora y sublimación de su imagen. Un pro- 
grama necesario hasta alcanzar un destino al servicio de la Monarquía, acorde con su estatus y con la trayectoria anterior de su familia. En el caso particular de Alburquerque, publicística, tratadística política, teatro y literatura celebrativa pudieron ser las bases de esa campaña de imagen para ganar la batalla de la opinión letrada tanto en la calle como en las covachuelas o en Palacio. De este modo, la edición de una Parte de la producción teatral de Moreto pudo jugar una baza que iba más allá de dar a conocer la obra del genial dramaturgo en letra impresa. La edición discurriría y tomaría cuerpo a través de las invisibles redes clientelares de un gran noble como Alburquerque y se convertiría en una pieza central del discurso que sirvió para afianzar y mejorar su imagen.

En vida de Moreto no volvió a editarse un volumen dedicado en exclusiva a sus obras teatrales. Pero su nombre y su producción volvieron a cobrar interés en fechas cercanas al momento de proclamación de la mayoría de edad de Carlos II (Ruiz Rodríguez 393) tras las tormentas políticas que describía al comienzo de este artículo y que dieron paso progresivamente al valimiento de Valenzuela (Hermant 299). Por lo que se deduce del contenido de los paratextos de su Segunda parte de comedias (Moreto 1676), esta se preparó a lo largo del mes de noviembre de 1675 y en este caso se dedicó al ilustre Sr. don Francisco Idiáquez Butrón Muxica Borja, Marqués de San Damián.

La circunstancia y motivación de la dedicatoria de este segundo volumen es completamente distinta de la del primero. Evidentemente ya no es Moreto sino el mercader de libros Francisco Duarte, quien prepara la edición y es él quien busca protector. Justifica las razones de la dedicatoria afirmando que con su patrocinio el teatro de Moreto podrá "sublimarse a la cumbre del aplauso" para aseverar más adelante que cree haber tenido dos virtudes con su iniciativa. La primera: "la elección de comedias por ser de cómico tan aplaudido y con justa razón celebrado". La segunda, por "el acierto en ampararme de la sombra de v.S.I. para que tenga todo el complemento de Grande en la Corte de la Fama" (\$\$2-4).

El dedicatario en esta ocasión fue, como he dicho, don Francisco de Idiáquez Butrón de Mújica Álava y Robles (1620-1687), III Duque de Ciudad Real en el Reino de Nápoles y VII Príncipe de Esquilache también en ese mismo reino. Títulos napolitanos que exhibió para ser Virrey de Valencia y de Aragón. Su perfil social, a pesar de ser el de un noble, no era ya el de un grande perteneciente a la más alta aristocracia (Sanz Camañes).

La dedicatoria redactada por el mercader de libros estaba orientada en su totalidad a recrear la genealogía a ratos fabulosa (Sanz Ayán) de Idiáquez, pri- 
mogénito y heredero en esos momentos del que era en 1675 el virrey de Valencia, ciudad en la que el mercader de libros estaba afincado. Tras describir al completo los títulos del padre y de la madre del dedicatario, lo que definía su nobleza según el relato era, precisamente, el origen y la sangre. Se trataba de visibilizar que era el hijo mayor del Excmo. Sr. don Francisco Idiáquez Múxica Butrón y Álava, duque de Ciudad Real, Conde de Aramoya, Tribiana, Barrica y de Mayalde, Príncipe de Esquilache, marqués de S. Damián y del Palier, señor de la Casa de Idiáquez Múxica y Butrón y Gentilhombre de la Cámara de S. Mg., Montero y Ballestero Mayor, además de virrey y capitán general que fue en el Reino de Aragón y que lo era ahora de la ciudad y reino de Valencia (1675). También aclaraba que se había casado en 1654 con la Excma. Sra. doña Francisca de Borja y Aragón, condesa de Mayalde y comendadora Mayor de Montesa que era citada expresamente para dar una visión completa de la genealogía de don Francisco Idiáquez.

En la reconstrucción del linaje que redacta el editor comienza por hacer memoria de los Idiáquez de quienes "delinear la grandeza de la casa [...] sería pretender enumerarle al sol los átomos y a todas luces quedar corta la más dilatada pluma". Tras colocar el origen de su solar en Tolosa, provincia de Guipúzcoa, quedan descritos como "eminentes soldados y "columnas de la Corona de España que tienen llenas las hojas de las historias de España de las hazañas de las hojas de sus espadas".

Cita expresamente dos personajes llamados ambos Alonso Idiáquez; el primero, servidor de Felipe II y Felipe III, comendador del hábito de Santiago (1596) y general de la caballería ligera de Lombardía, que a su vez era hijo de don Juan Idiáquez, comendador mayor de León, presidente del Consejo de Órdenes Militares y del Consejo de Estado, además de embajador de Felipe II que lo fue junto con don Juan de Borja, duque de Gandía, para sosegar las alteraciones de Génova. El otro Alonso Idiáquez citado, es el que en 1637 pasó a la Rochele en servicio de su majestad y después a Flandes y las Indias donde fue capitán general de Tucumán.

Asimismo, el mercader de libros reconstruyó las genealogías de las otras dos casas de las que descendía el dedicatario, la de Múxica y la de Butrón. Con respecto a la de Múxica citaba como cabeza del linaje a Juan Galíndez, mayorazgo de la casa de Avendaño, señor de Aramayoa que por sucesivos casamientos demostraba ser descendiente nada menos que del Santo Rey don Fernando y de doña Juana Manuel, reina de Castilla, esposa de Enrique II el de las mercedes y de doña Constanza Manuel, reina de Portugal, 
mujer de Pedro el justiciero. Con respecto a la Casa de Butrón, de nuevo se encuentran ascendencias de santos pues tras describir múltiples enlaces hace descender al dedicatario de "Madama Sánchez" hija del rey de Nápoles Alfonso II el cual dio a su hija el principado de Esquilache y, una vez extinguida la línea masculina, quedó el principado en doña Ana de Borja la cual casó con don Francisco de Borja, nieto de san Francisco de Borja, gentil hombre de la cámara del rey Felipe III, comendador de Azuaga en la orden de Santiago y Virrey del Perú. La construcción genealógica da una apariencia de rigor y precisión con numerosas referencias informativas en los márgenes, pero con todo, aparecen como parientes y ascendientes nada menos que Fernando III el Santo, dos reinas -una de Castilla y otra de Portugal-, un rey de Nápoles y el santo por excelencia de la grandeza de España, san Francisco de Borja (Terrasa 57-60). Una carta de presentación bruñida que le permitía hacerse visible en la corte en una coyuntura política propicia para encontrar nuevos acomodos. Recordemos que era el momento en el que se iba a proclamar la mayoría de edad de Carlos II. Junto a todos los títulos que se visibilizan, tienen un hueco especial los cargos palatinos que el padre desempeñaba y que lógicamente en la enumeración se colocan por delante del puesto de virrey.

Fijándonos ya directamente en el perfil de servicio de don Francisco de Idiáquez, había sucedido como virrey de Aragón a Nicolás Ludovico que era príncipe de Piombino (Pomblin) y de Benussia, en Italia. Alguien con un perfil nobiliario parecido al suyo, ya que también los títulos eran napolitanos y por tanto en un rango inferior a la nobleza castellana. Fue nombrado virrey por Felipe IV el 31 de agosto de 1661 y confirmado ya durante la minoría de Carlos II en 1665. Le sucedió en el cargo, por un periodo de cinco meses, Pedro Antonio de Aragón, capitán general de Artillería de los Reales Consejos de Guerra y de Estado.

Durante su virreinato en Aragón desarrollado entre 1661 y 1667, auspició las relaciones cordiales con las instituciones propias de aquel reino, especialmente con la Diputación y los jurados de Zaragoza (Sanz Camañes). De hecho, durante la década de 1660, tanto el Reino de Aragón como la ciudad de Zaragoza contribuyeron con distintos servicios económicos y militares con destino al frente de Portugal. Fortaleció las bases del tradicional vínculo pactista, gracias al acuerdo y la negociación propiciada entre los agentes del Reino y de la Corona, desde mediados del siglo XVII, pero es curioso que ninguno de estos extremos y capacidades políticas se visibilice en la dedicatoria. 
La finalización de su mandato coincidió con el inicio de la Guerra de Devolución con Francia, entre 1667 y 1668. Era una época de tormentas políticas en las que las facciones cortesanas habían tenido múltiples causas de enfrentamiento. Los servicios que asimilaban a los nobles a una u otra facción podían quitar más que dar si en algún momento esa facción resultaba damnificada y por eso los valores genealógicos parecían un mérito seguro a la hora de hacerlos visibles para conseguir un nuevo puesto en la corte o al servicio de la Monarquía. La visibilización de esos servicios a partir de un patrocinio cultural seguro -un exitoso y ya desaparecido autor de comedias de prestigio en palacio como era Moreto-, parecía una buena y segura apuesta.

Pero aún descendió un escalón más la obra impresa de Moreto en la calidad social de sus valedores. De un grande a un titulado más reciente, aunque ambos fueron virreyes al servicio de la Monarquía, pasó a quedar bajo los auspicios de un simple letrado. Inmediatamente después de la aparición de la $S e$ gunda parte de sus comedias a cargo del vecino de Valencia Francisco Duarte, en Madrid el impresor y mercader de libros Andrés García de la Iglesia (Gómez Sánchez-Ferrer) decidió poner en manos del lector una nueva edición de la Primera parte de comedias (Moreto 1677). Este mercader dedicó sus producciones tanto a libros de literatura y teatro como a manuales de exorcismos, libros de sermones, actas de academia o tratados de historia y doctrina religiosa primando, por encima de todo, el interés comercial.

La nueva edición de la Primera parte de las comedias de Moreto se dedicaba a don Joseph de Cañizares, procurador de los reales consejos y al parecer padre del homónimo y célebre dramaturgo de la primera mitad del siglo XVIII nacido en 1676 (Cobo 133) José de Cañizares. Al hacerlo se trataba de pagar alguna deuda o quizá de subvencionar la obra de alguna manera. En ella el dedicatario conseguía dar lustre a sus orígenes -aunque de forma tan burda que resulta satírica- ya que tanto los argumentos como la edición fueron poco cuidados.

El librero afirmaba hacerla "porque viéndome con pocos medios le doy a V.M. en este libro (y a quien suplico lo admita) una tan pequeña reliquia de lo que le estoy debiendo, que solo es un deseo y voluntad que tengo de servirle". De modo retórico se disculpaba por dedicarle una obra que no era "Ni de prosa larga, ni elocuente, ni de doctrina, ni de erudición" mientras dejaba muy claramente especificado que el dedicatario le había ayudado alguna vez de forma material pues afirmaba que "le viene por sangre y por herencia el soldar quiebras tales como las mías pues dice el proverbio castellano que no hay mejor cirujano que el bien acuchillado" (Moreto 1677). 
A partir de aquí la reconstrucción fabulosa del linaje de los Cañizares -que en este caso parece que tenían ascendencia conversa-, da pie para dar lustre de forma desmesurada a sus ancestros de modo que el texto adopta un tono semi burlesco, no sabemos si de forma intencionada o no. Como se trataba de un letrado, salía a colación la querella de las armas y las letras e inmediatamente después comenzaba la reconstrucción genealógica de Cañizares cuyo mejor referente por elevación era don Pelayo:

Trae V.M. su abolengo desde los tiempos de Pelayo y de uno de aquellos cavalleros del territorio de Cangas de Tync[e]o (a quien llaman los privilegios Cañizas) que salieron a la infausta montería donde perdió la vida el Rey León, Favila, entre los brazos de un oso. No se sabe su nombre pero se sabe que fue el primero que topó muerto al rey y al oso cebándose en su sangre entre unos madroños con cuyo espectáculo, arrebatado de la ira, viéndose con el venablo en la manos lo atravesó por el cuerpo. Deste principio tan sangriento como generoso es Cañizas, comenzó a sobresalir el apellido de Cañizares. (Moreto 1677)

Este episodio era el mejor modo de ilustrar el escudo de armas del letrado que aun siendo también muy tosco en su diseño, se repetía por dos veces en la edición; tanto en la portada como en la dedicatoria. A partir de datos aportados por Juan Pablo Mártir Rizo en la Historia de Cuenca, afirmaba que el escudo portaba las cañas que había en el lugar donde murió el rey Fabila y se unían en el oso, cuyo blasón fue de allí en adelante unas cañas en campo azul, un madroño en campo verde y un oso en campo rojo.

A partir de aquí una fabulación parecida le hace coincidir con algunos Cañizares conocidos que al parecer estuvieron en las batallas más simbólicas de la construcción mítica de la propia Monarquía española:

Hable por todos los difuntos sus antecesores, después de cuatrocientos años el bravo Andrés Cañizares, capitán de 100 soldados con que bajó de las Asturias en edad de 33 años para la toma de la ciudad de Cuenca en cuya conquista puso el rey don Alonso el Octavo la mira. Su hijo Juan de Cañizares, sirviéndose al rey don Alonso de paje desde 12 años se halló en la batalla de las Navas de Tolosa en 1212. Lope de Cañizares lo hizo en la batalla del Salado en tiempos de Alfonso XI. Otro Lope de Cañizares se halló en la defensa de Malta y un Julio Cañizares se halló en las guerras de Flandes en el cerco de Amberes y en el de Mastrich. (Moreto 1677) 
En cuanto a los enlaces matrimoniales, son los que le conectan con su actual oficio al servicio del rey pues eran "nobilísimos en Castilla, Navarra y Aragón y digo nobles, no solo por lo belicoso sino también por la toga, pues en Cuenca fueron alcaldes las cinco primeras generaciones después de Andrés de Cañizares llegando esta inclinación honrosa a la persona de V.M." (Moreto 1677).

Similar descenso en la categoría social de los dedicatarios de la obra de Moreto lo encontramos en 1681 en la edición de su Tercera parte de comedias (Moreto 1681). Estaba dedicada al Señor Francisco Martínez de la Serna, escribano de Provincia de la Casa y Corte de S. Mg., del que no hemos encontrado más noticias que las relativas a su quehacer notarial dando fe de la apertura de un testamento (Vilar 452). Es Antonio de Zafra, Criado de S. Mg. en la Real Volatería, el que promovió esta edición y sabemos que lo había hecho con otras obras de Moreto probablemente por ser un gran aficionado a su obra. Pero es el mercader de libros Juan Fernández el que comercializó la edición en su tienda situada en la portería del colegio Imperial de la Compañía de Jesús y para la que obtuvo licencia del Consejo por una vez el 30 de agosto de 1681 (Barrera 278).

A modo de conclusión, con este trabajo no se pretende negar que la edición de las obras de Moreto, tanto en vida como tras su muerte en la Segunda y Tercera Partes, tengan una dinámica literaria propia en la que se inserta la estrategia de difusión de la obra del poeta dramático en el primer caso y de la de los mercaderes de libros en los demás. Pero también se debe tener en cuenta la instrumentalización de la que pudieron ser objeto estas ediciones por parte de los dedicatarios y quizá mecenas, en un contexto social y político determinado. En este sentido parece que existe una gran diferencia de estrategia cuando la dedicatoria la hizo el poeta, en nuestro caso Moreto, que cuando la pergeñaron los mercaderes de libros.

En el primer caso, es posible detectar la existencia de clientelas alrededor de un alto noble, dentro de cuyos engranajes el dramaturgo Moreto ocupó un lugar. Detectar esa red en la que el creador se inserta tiene, desde el punto de vista de la historia social y cultural, una importancia capital. En este sentido la identificación y biografía del dedicatario de las obras puede dar valiosas pistas respecto a la "utilidad social" de la edición en un momento concreto. Como hemos visto, en el caso de la edición de la Primera parte de las comedias de Moreto, la obra parece insertarse en un programa más general de construcción de la imagen ideal del VIII duque de Alburquerque, que se encontraba en plena campaña de méritos para alcanzar destinos políticos de altura. En seme- 
jante contexto sociocultural la edición de la obra de Moreto no sería un acto de protección aislado a un literato que se agota en sí mismo, sino que formaría parte de una estrategia de visibilidad y autopromoción de un reconocido mecenas que va más allá de la calidad y cantidad de los textos dramáticos, poniéndolos en conexión con otros géneros literarios, otras obras y otros autores para su mayor gloria. Este ángulo de observación obliga a que el hilo conductor de nuestro relato no sea el autor, sino el mecenas-dedicatario siguiendo un ritmo de reconstrucción en el que la diacronía del contexto político y cultural resulta clave. En la reconstrucción de la red cultural/clientelar de Alburquerque, girarían también en una época estrictamente coetánea a los tiempos en los que trató con Moreto, los escritores López de Vega, Juan de Guevara e incluso parte del grupo de publicistas que trabajaron con don Juan José de Austria como Fabro Bremundán o sus colaboradores.

Caso muy distinto sería el de los editores de la obra de Moreto tras su muerte. En ellos la prioridad del interés material para lograr la subvención de la edición parece obvia, aunque la utilidad directa del dedicatario siga siendo la de la promoción pública de su imagen. Desde el noble más reciente hasta el hidalgo letrado, todos se sirven del paratexto laudatorio para bruñir sus orígenes y apellidos en una relación inversamente proporcional en calidad al tono del elogio y al origen de los ancestros del dedicatario. En las ediciones de las obras de Moreto acometidas por diversos mercaderes de libros tras su fallecimiento, parece difícil detectar la existencia de redes clientelares que propiciaran la actividad editorial. Sí parece más perceptible la existencia de un intercambio comercial en el que la promoción de la imagen de gentes en proceso de ascenso social parece la primera exigencia, a tenor de la imagen de fantasía que construyen para validar su situación social presente.

Por último, aunque la relación que los editores y sus dedicatarios tuvieron con la obra de Moreto durante el siglo XVII puede parecernos, desde el punto de vista expuesto, parasitaria, en realidad resultó simbiótica pues aun en los casos en que estas ediciones fueron poco cuidadas, facilitaron su vigencia como autor dramático.

\section{OBRAS CITADAS}

Acquier, Marie-Laure. "Los tratados en prosa de Antonio López de Vega: aproximación al discurso político en el siglo XVII". Cuadernos de Historia Moderna 24 (2000): 85-106. 
Agulló Cobo, Mercedes. "Don José de Cañizares”. En torno al teatro del Siglo de Oro: ХVI-ХVII Fornadas de Teatro del Siglo de Oro. Almería: Instituto de Estudios Almerienses, 2004. 133-52.

Barrera y Leirado, Cayetano Alberto de la. Catálogo bibliográfico y biográfico del Teatro Antiguo Español desde sus orígenes hasta mediados del siglo XVIII. Madrid: Imprenta y Estereotipia de M. Rivadeneyra, 1860.

Cotarelo y Mori, Emilio. "La bibliografía de Moreto". Boletín de la Real Academia Española 14 (1927): 449-94.

Fabro Bremundan, Francisco. Historia de los hechos del Serenísimo Señor don Fuan Fosé de Austria en el Principado de Cataluña. Zaragoza: Diego Dormer, vol. 1, 1673.

Farré, Judith. "Teatro y poder en el México Virreinal: La dramática panegírica en torno a la figura del Virrey". Permanencia y destino de la literatura novohispana: Historia y Crítica. Eds. José Pascual Buxó, Dalia Hernández Reyes y Dalmacio Rodríguez Hernández. México: Universidad Autónoma de México, 2006. 225-36.

Fernández de la Cueva, Francisco. Carta del excelentissimo señor don Francisco Fernandez de la Cueua, Duque de Albuquerque [...] Capitan general de las galeras de España: escrita a su hermano don Gaspar de la Cueua Enriquez, Maese de Campo en el Real Exercito de Catluña [sic]. Zaragoza: Diego Dormer, 1650.

Fernández de la Cueva, Francisco. Carta del excellentissimo señor Duque de Alburquerque, Capitan General de las galeras de España escrita al excellentissimo señor d. fr. Pedro de Vrbina, Arçobispo de Valencia, Virrey y Capitan general deste Reyno: en que se da quenta de la vitoria ... en las costas de Cataluña ... contra quatro nauios que venian a socorrer ... al exercito de Francia ... para ... la plaça de Tortosa. Valencia: Silvestre Esparsa, 1650.

Flórez Asensio, María Asunción. "El Coliseo del Buen Retiro en el Siglo XVII: teatro público y cortesano". Anales de Historia del Arte 8 (1998): 171-97.

Gómez Sánchez-Ferrer, Guillermo. "Los «once entremeses» de Andrés García de la Iglesia: de teatro y pliegos sueltos", Rilce 30.2 (2014): 402-25.

Hermant, Héloïse. "¿Pérdida de España? Epifanía de un espacio público y reconfiguración de identidades en la España de Carlos II". Espacio, Tiempo y Forma. Serie IV, Historia Moderna 27 (2014): 295-325.

Israel, Jonathan Irvine, y Roberto Gómez Ciriza. Razas, clases sociales y vida política en el México colonial, 1610-1670. México: FCE, 1980.

Laspéras, Jean-Michel. "Manuales de educación en el Siglo de Oro”. Bulletin bispanique 97.1 (1995): 173-85. 
Lobato, María Luisa. “Cronología de Loas, entremeses y bailes de Agustín Moreto". Criticón 46 (1989): 125-34.

López de Vega, Antonio. El perfeto Señor. Madrid: Viuda de Alonso Martín, 1626. López de Vega, Antonio. El perfeto señor. Sueño político, con otros varios discursos y últimas poesías varias. Madrid: Imprenta Real, 1652.

Maestro Castañeda, Juan Carlos. Lope Diéz de Aux y Armendáriz. 12 de abril de 2019. http://dbe.rah.es/biografias/15264/lope-diez-de-aux-y-armendariz.

Maura y Gamazo, Gabriel. Carlos II y su corte: ensayo de construcción biográfica. 2 vols. Madrid: BOE/RAH, 2018.

Melo, Francisco de. "Diario de lo que hizo Francisco de Melo desde que salió hasta ganar la Bassea. Madrid y Junio 15 de 1642". Memorial Histórico Español. Colección de Documentos, Opúsculos y Antiguedades. Madrid: RAH 16, 1862. 396-415.

Moll, Jaime. "Les éditions de Quevedo dans la donation Olagüe à la Bibliothèque de la Casa de Velázquez". Mélanges de la Casa de Velázquez 16.1 (1980): 457-94.

Moreto, Agustín. Primera parte de comedias de don Agustín Moreto y Cabana. Madrid: Diego Díaz de la Carrera, a costa de Mateo de la Bastida, 1654.

Moreto, Agustín. Primera parte de comedias de don Agustín Moreto y Cabana. 2. ${ }^{a}$ ed. Madrid: Andrés García de la Iglesia, 1677.

Moreto, Agustín. Segunda parte de comedias de don Agustín Moreto. Valencia: Imprenta de Benito Macè, a costa de Francisco Duart[e] mercader de libros, 1676.

Relacion de la gran vitoria que han tenido las galeras de España, siendo General dellas el... Duque de Alburquerque. Madrid: Diego Días, 1650.

Relacion del feliz sucesso que parte de nuestra caualleria governada y asistida por sv General el señor Duque de Alburquerque tuvo contra la del enemigo, governandola el Marques de la Fara entre Villafranca de Panadès y Martorel. Madrid: Alonso de Paredes, 1649.

Relación puntual y verdadera en que se quenta el sucesso que se ba tenido en la empressa de San Feliu, gobernada y executada por el Serenisimo Señor D. Fuan, asistido del duque de Alburquerque, capitán General de las Galeras de España y del marqués de Bayona de la esquadra de Sicilia. Lunes 17 de junio de 1652. s.f. s.l.

Rodríguez Villa, Antonio. El duque de Alburquerque en la Batalla de Rocroy. Impugnación a un artículo del duque de Aumale sobre esta batalla y noticia biográfica de aquel personaje. Madrid: Imprenta de D. G. Hernando, 1886. 
Rubio Mañé, Jorge Ignacio. El Virreinato I: orígenes y jurisdicciones y dinámica social de los virreyes. México: UNAM/FCE, 1983.

Ruiz Rodríguez, Ignacio. Don Fuan Fosé de Austria en la Monarquía Hispánica. Madrid: Dykinson, 2007.

Sanz Ayán, Carmen. "La imagen de la nueva nobleza titulada en el reinado de Carlos II a través de las dedicatorias". L'Espagne de Charles II, une modernité paradoxale (1665-1700). Ed. Marina Mestre Zaragoza. Paris: Classiques Garnier, 2019. 205-31.

Sanz Camañes, Porfirio. Francisco de Idiáquez Butrón de Mújica Álava y Robles. 3 de marzo de 2019. http://dbe.rah.es/biografias/20638/francisco-deidiaquez-butron-de-mujica-alava-y-robles.

Schmidhuber, Guillermo. "Juan de Guevara, poeta y comediógrafo coetáneo de sor Juana”. Tintas: Quaderni di Letterature Iberiche e Iberoamericane (2013): 59-74. 30 de octubre de 2018. https://riviste.unimi.it/index.php/ tintas/article/view/3677.

Tercera relación del Feliz suceso y nueva vitoria que ba tenido el Excmo Señor duque de Alburquerque contra las Armas de Francia. Sevilla: Juan Gómez de Blas, 1649.

Terrasa Lozano, Antonio. "Honra y gloria de todos los cortesanos de la Corte del Cielo: los parientes del Sol, de San Ignacio de Loyola y de San Francisco de Borja: de la nobleza de los santos y la santidad jesuita como capital simbólico de la nobleza (siglos XVI-XVIII)". Lusitania Sacra 32 (2015): 53-79.

Vargas Zúñiga, Antonio (Marqués de Siete Iglesias). "Títulos y Grandezas del reino". Hidalguía: Revista de Genealogía, Nobleza y Armas 5 (1954): 212-35.

Vilar y Pascual, Luis. Diccionario Histórico genealógico y heráldico de las familias ilustres de la Monarquía Española. Madrid: Imprenta de D. Francisco Sánchez, a cargo de D. Agustín de Espinosa, 1862.

Zugasti, Miguel. "Vicisitudes de la escritura teatral en el Siglo de Oro: dramaturgo, censores cómicos e impresores alrededor del texto de $E l$ poder de la amistad, de Moreto". Moretiana: adversa y próspera fortuna de Agustín Moreto. Eds. María Luisa Lobato y Juan Antonio Martínez Berbel. Madrid: Iberoamericana / Frankfurt a.M.: Vervuert, 2008. 39-72. 